\title{
REPERCUSSÕES DO USO DE CRACK NO COTIDIANO FAMILIAR*
}

Daiana Foggiato de Siqueira ${ }^{1}$, Claudete Moreschi² ${ }^{2}$, Dirce Stein Backes ${ }^{3}$, Valéria Lerch Lunardii, Wilson Danilo Lunardi Filho $^{4}$, Camila Biazus Dalcin ${ }^{5}$

RESUMO: Objetivou-se conhecer as repercussões do uso de crack no cotidiano familiar. Utilizou-se o método Grounded Theory, conduzido por meio da entrevista em profundidade, com 15 familiares de usuários internados em uma unidade de desintoxicação hospitalar da região central do Rio Grande do Sul, entre maio e dezembro de 2010. Os dados analisados resultaram na categoria central Sobrevivendo em condições de incerteza e nas subcategorias Contextualizando o fenômeno crack no ambiente familiar; Percebendo as causas da luta pela sobrevivência; Evidenciando os fatores intervenientes positivos e negativos; e Deparando-se com as consequências. Conclui-se que os familiares de usuários de crack sentem incertezas, vergonha, culpa, temores de toda ordem, e impotência diante do inesperado. É preciso repensar o ser e o agir dos profissionais de saúde, reconhecendo as incertezas, as desordens e as contradições vivenciadas por esses familiares. PALAVRAS-CHAVE: Pesquisa em enfermagem; Cocaína crack; Família; Estratégias; Saúde pública.

\section{REPERCUSSIONS FROM THE USE OF CRACK IN DAILY FAMILY LIFE}

ABSTRACT: The aim was to know the repercussions of crack cocaine use in daily family life. The Grounded Theory method was used, conducted through in-depth interview, with 15 family members of drug users who were admitted to a hospital detoxification unit in the central region of Rio Grande do Sul between May and December 2010. Once analyzed, the data resulted in the main category Living in conditions of uncertainty and in the subcategories Contextualizing the crack cocaine phenomenon in the family environment; Perceiving the causes of the battle for survival; Demonstrating the positive and negative intervenient factors; and Facing the consequences. It is concluded that crack cocaine users' family members feel uncertainty, guilt, all kinds of fears, and helplessness in the face of the unexpected. It is necessary to rethink how health professionals should be and act, recognizing the uncertainties, chaos and contradictions lived through by these family members. KEYWORDS: Research in Nursing; Crack Cocaine; Family; Strategies; Public health.

\section{REPERCUSIONES DEL USO DE CRACK EN EL COTIDIANO FAMILIAR}

RESUMEN: El objetivo de este trabajo fue conocer las repercusiones del uso de crack en el cotidiano familiar. Fue utilizado el método Grounded Theory, conducido por medio de la entrevista en profundidad, con quince familiares de usuarios internados en una unidad de desintoxicación hospitalar de la región central de Rio Grande do Sul, entre mayo y diciembre de 2010. Los datos analizados resultaron en la categoría central Sobreviviendo en condiciones de incertidumbre y en las subcategorías Contextualizando el fenómeno crack en el ambiente familiar; Percibiendo las causas de la lucha por la supervivencia; Evidenciando los factores intervinientes positivos y negativos; y Deparándose con las consecuencias. Se concluye que los familiares de usuarios de crack tienen incertidumbres, vergüenza, culpa, temores de todo orden, e impotencia delante del inesperado. Es necesario repensar el ser y el actuar de los profesionales de salud, reconociendo los incertidumbres, los desórdenes y las contradicciones vividas por eses familiares.

PALABRAS CLAVE: Investigación en enfermería; Cocaína, crack; Familia; Estrategias; Salud pública.

*Pesquisa financiada pela Fundação de Amparo à Pesquisa do Rio Grande do Sul - FAPERGS.

${ }^{1}$ Enfermeira. Pós-Graduanda em Urgência, Emergência e Trauma pela Associação Educacional Frei Nivaldo Liebel. Membro do Grupo de Estudos e Pesquisa em Empreendedorismo Social da Enfermagem e Saúde - GEPESES.

${ }^{2}$ Enfermeira. Mestranda pelo Programa de Pós-Graduação em Ambiente e Desenvolvimento do Centro Universitário de Lajeado. Membro do GEPESES. ${ }^{3}$ Enfermeira. Doutora em Enfermagem. Professora do Curso de Enfermagem do Centro Universitário Franciscano UNIFRA. Líder do GEPESES. ${ }^{4}$ Enfermeiro. Doutor em Enfermagem. Professor da Escola de Enfermagem da Universidade Federal do Rio Grande - EENF/FURG. ${ }^{5}$ Acadêmica de Enfermagem pela UNIFRA. Bolsista PIBIC/CNPq. Membro do GEPESES.

Autor correspondente:

Daiana Foggiato de Siqueira

Centro Universitário Franciscano

Av. Ângelo Bolson, 730 - 97070-000 - Santa Maria-RS-Brasil.

E-mail: daianasiqueira@yahoo.com.br
Recebido: 12/09/2011 Aprovado: 04/06/2012

Cogitare Enferm. 2012 Abr/Jun; 17(2):248-54 


\section{INTRODUÇÃO}

O consumo de crack já pode ser caracterizado, na atualidade, como um fenômeno devastador, com grandes repercussões não só para os usuários, mas também para as famílias e a comunidade em geral. Tanto no âmbito nacional quanto internacional, é notório o aumento do seu consumo, com associação a diferentes tipos de drogas, principalmente as sintéticas. No Brasil, as drogas que são consumidas com maior frequência são o álcool, os inalantes, a cocaína e seus derivados, mais especificamente o crack $^{(1-2)}$.

Dados do Ministério da Saúde apontam que no Brasil existem aproximadamente 600 mil usuários de crack, sendo que, inicialmente, o foco do consumo dessa droga concentrava-se no Município de São Paulo, disseminando-se para as demais cidades brasileiras $^{(3)}$. No Estado do Rio Grande do Sul, particularmente, o aumento do número de usuários cresceu visivelmente. Dados registram que de 55 mil usuários, no ano de 2008, o Estado registrou um acréscimo para 60 mil, no ano de $2009^{(4)}$. O que fazer para combater o seu consumo e o aumento crescente de usuários? Como agir com os cerca de 60 mil usuários que já fazem parte do cotidiano de muitas famílias e da sociedade em geral?

Aliar intervenções resolutivas com atitudes proativas, com vistas a reduzir as manifestações diretas do uso/abuso dessa e de outras drogas, por meio de ações gerais voltadas a minimizar os prejuízos secundários ao processo de drogadição constituem um grande desafio, tanto para os pesquisadores quanto para os órgãos governamentais. Desse modo, antevê-se que medidas preventivas, como também de tratamento e reabilitação, somente terão êxito mediante políticas de educação e de saúde inclusivas, voltadas para os indivíduos, famílias e comunidade em geral. É preciso considerar que a família ocupa um espaço importante e essencial, por ser a base da estruturação dos seres humanos, potencialmente agregadora e integradora dos mais diferentes movimentos da vida diária e comunitária ${ }^{(5-7)}$.

Reconhece-se que as famílias dos usuários de crack, pelo seu envolvimento profundo com o dependente, precisam ser acolhidas e acompanhadas por profissionais qualificados. Nesse contexto, os profissionais de saúde, entre eles o enfermeiro, podem vir a desempenhar um papel importante, tanto pela compreensão dos drogaditos em seu contexto real, quanto pela capacidade de resgatar os vínculos entre eles e seus familiares.
Em face do impacto devastador do crack no cotidiano familiar e como profissionais da saúde preocupados com as repercussões crescentes do seu consumo nos diferentes setores sociais, questionamo-nos: Quais as repercussões do uso do crack no cotidiano familiar? Objetivou-se, com este estudo, conhecer as repercussões do uso de crack no cotidiano familiar.

\section{MÉTODO}

Trata-se de um estudo qualitativo, exploratório, orientado pelo método Grounded Theory ${ }^{(8-9)}$. Neste método, a coleta e a análise de dados constituem-se num processo sistemático, no qual os dados são analisados comparativamente.

Os dados foram coletados por meio da entrevista em profundidade, gravada e a seguir transcrita. Participaram do estudo 15 familiares de usuários de crack, sendo representados por 10 mães, dois pais e três avós, considerando-se a disponibilidade, a aceitação e a localização das moradias.

Na realização das entrevistas levou-se em conta as hipóteses que emergiram das entrevistas anteriormente realizadas com 26 usuários de crack, internados em uma unidade de desintoxicação hospitalar, localizada na região central do Rio Grande do Sul. Tais hipóteses estavam relacionadas à desestruturação familiar, a pais usuários de drogas e ao desemprego. Com o objetivo de validar as informações e conhecer o contexto familiar dos usuários, foi realizada uma visita às famílias. As entrevistas com os familiares foram realizadas nos próprios domicílios, tendo como questão norteadora: Fale-nos sobre como tem sido o seu dia a dia enquanto familiar/responsável de um usuário de crack.

A coleta e a análise de dados foram processadas de forma sistemática e comparativa entre os meses de maio e dezembro de 2010, conforme prevê o método de pesquisa em questão. A análise comparativa e sistemática dos dados tem por objetivo conhecer o ambiente, codificar os dados, formar as categorias, reduzir o número de categorias e identificar a categoria central ${ }^{(10)}$.

O projeto foi aprovado pelo Comitê de Ética do Centro Universitário Franciscano, sob o n. 279/2009, registro CONEP 1246. Os critérios éticos de pesquisa com seres humanos foram observados e processados à luz da resolução do Conselho Nacional de Saúde n. 196 , de 10/10/96 e n. 251 de 07/08/97 $7^{(11)}$. Os participantes e/ou os seus responsáveis, após esclarecimento dos propósitos do estudo, assinaram o termo de consentimento livre e esclarecido. Para garantir a 
privacidade e anonimato, as falas dos participantes foram identificadas no texto, por meio da letra ' $F$ ' (familiares), seguidas de um número que corresponde à ordem das entrevistas.

\section{RESULTADOS}

O método adotado possibilitou construir hipóteses testáveis e gerar construtos teóricos, que conduziram à delimitação da categoria central: Sobrevivendo em condições de incerteza e subcategorias Contextualizando o fenômeno crack no ambiente familiar; Percebendo as causas da luta pela sobrevivência; Evidenciando os fatores intervenientes positivos enegativos; Deparando-se com as consequências.

A categoria central Sobrevivendo em condições de incerteza evidencia que o uso do crack causa impacto direto no cotidiano familiar, visto que a família passa a conviver em condições, na maioria das vezes, de total incerteza, desordem e contínua necessidade de reorganização. A incerteza expressa-se, concretamente, por meio de sentimentos de insegurança, medo, dor e crise familiar, os quais repercutem nas relações e interações entre todos os membros da família e comunidade.

A figura 1 apresenta, de forma esquemática, o processo de integração das subcategorias que deram origem à categoria central Sobrevivendo em condições de incerteza.

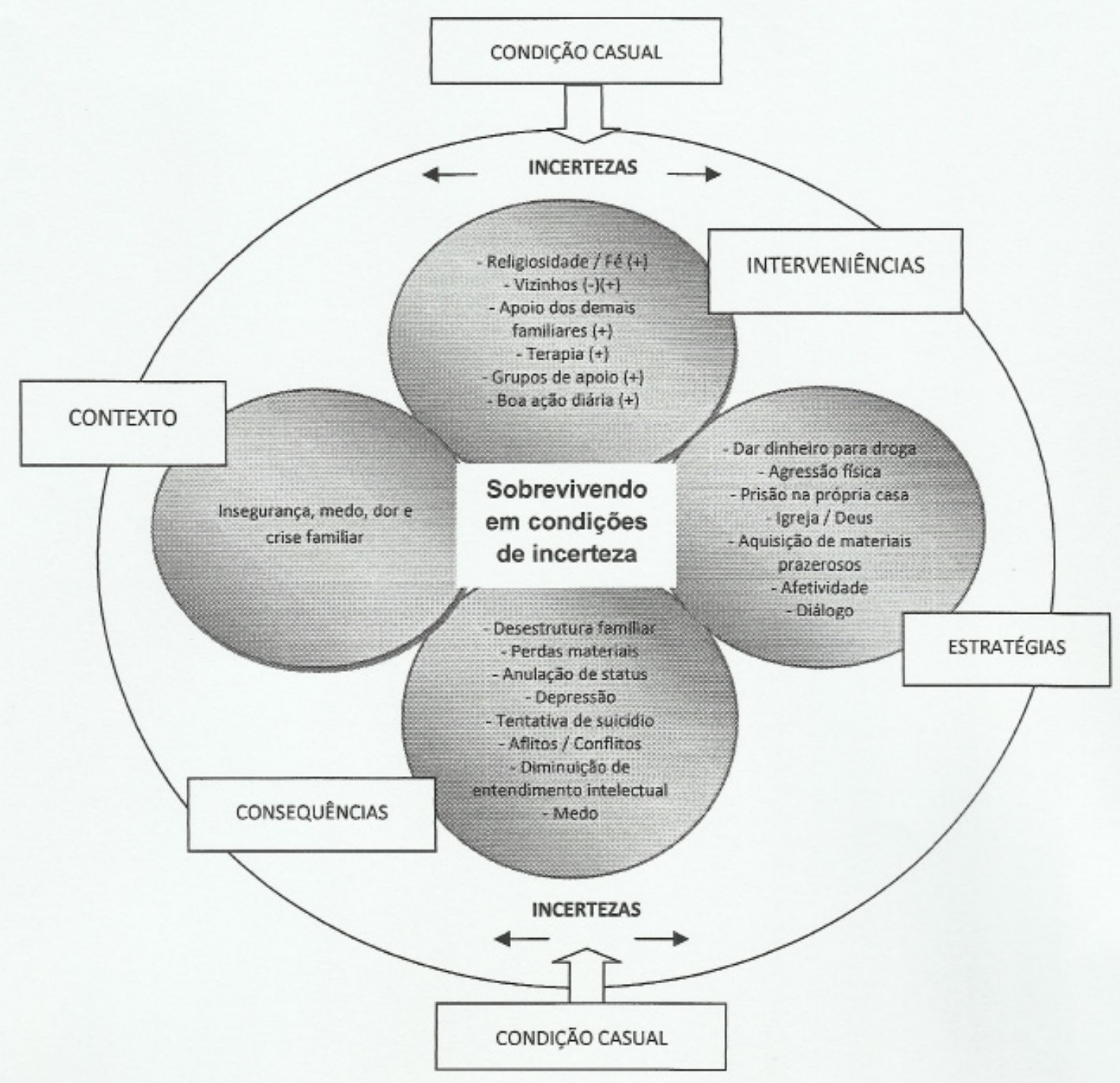

Figura 1- Sobrevivendo em condições de incerteza. Rio Grande do Sul, 2010 


\section{Contextualizando o fenômeno crack no ambiente familiar}

O crack é apreendido pela família como um fenômeno devastador e desagregador por gerar situações de incerteza e, na maioria das vezes, desordem no ambiente familiar, por desconhecerem as perspectivas de futuro, tanto do usuário da droga quanto da própria família, conforme pode-se perceber nas seguintes falas:

Olha! Foi muito dificil, para mim, saber que meu filho perdeu todo o futuro dele. Perdeu tudo a que ele tinha direito. Agora, não sei o que vai acontecer com ele e com a familia. (F1)

Eu não me sentia muito bem. Eu sabia que ele estava na rua, principalmente de noite [...] que aquilo ali deve ser um pesadelo. Mas eu não ia saber, se alguém tinha feito alguma coisa, se alguém tinha matado ou se ele estava vivo. (F6)

Pode-se inferir que os familiares têm consciência das consequências que a droga causa, ou pode causar. Relatam a incerteza, diante do futuro do familiar drogadito e a insegurança em saber se terá ou não uma vida "normal".

\section{Percebendo as causas da luta pela sobrevivência}

Os familiares, em geral, demonstraram grandes lutas e enfrentamentos, tanto pelo convívio direto com o usuário, quanto pelos sentimentos de incerteza e insegurança em relação ao futuro. Reconhecem que precisam, constantemente, "remar contra as correntezas" do medo, do desconhecido e dos próprios valores e crenças.

Teve um tempo em que ele estava cinco meses, no presidio, por uma bobagem. Eu paguei horrores de drogas, lá dentro, porque lá eles são obrigados a usar, senão, eles são marcados [...]. Agora, ele está na clínica há mais de 100 dias, e eu estou, assim, muito aflita. Não sei o que fazer com ele. (F4)

Percebe-se que a dependência química resultante do uso do crack induz o desenvolvimento de atitudes desesperadoras e, muitas vezes, equivocadas por parte dos próprios familiares, na busca de proporcionar segurança. Em outras palavras, o receio de surtos devido à vontade intensa provocada pela droga, direciona-os a adotarem condutas que contradizem o propósito de ajuda ao membro dependente. Em alguns casos o familiar acaba bancando a aquisição da droga, com o pensamento voltado a manter o familiar drogadito com sua integridade física preservada, afastando-o de situações de risco iminente.

\section{Evidenciando os fatores intervenientes positivos e negativos}

São diversos os fatores que contribuíram para a continuidade, ou não, da luta pela sobrevivência do familiar drogadito, bem como à manutenção da própria estrutura familiar. Pode-se dizer que alguns fatores contribuíram de forma favorável, ou seja, que proporcionaram a estruturação necessária para a família seguir em frente, com a fé em Deus, conforme expresso por mães. Outros apareceram de forma desfavorável, intervindo de forma negativa no processo, agravando ainda mais a situação do contexto familiar:

Ser mãe de dependente químico [...]. Sabe? É muito difícil. Ele destrói toda a família, toda a relação social. Tem a vizinhança, o ambiente em que tu vives na família. Ninguém aceita! O meu irmão e a minha irmã são os únicos que me dão apoio moral, porque apoio financeiro, eu não tenho de ninguém [...]. A minha única certeza é Deus. (F4)

Eu digo: Deus é que sabe [...]. Eu acredito muito que, na intervenção de Deus, que vai ter alguém ou algumas pessoas que vão conseguir fazer com que ele realmente saia dessa. Eu acho que, por eu sempre acreditar em Deus, é que tenho força. Então, está ai a esperança. Se vai acontecer ou não vai [...] Eu sempre digo: está nas mãos de Deus. (F5)

Eu fui para o grupo dos familiares e para o CAPS, além disso, eu tenho uma psicóloga e uma psiquiátra para que eu consiga me manter em pé. Porque é muito, muito, muito difícil conseguir se manter viva, sendo mãe de um usuário de drogas. (F11)

Acredito que estou em pé ainda porque tenho como meta, todos os dias, praticar uma boa ação [...]. Assim, me sinto confortada em saber que consigo proporcionar o bem para os outros. (F15)

Percebe-se que a religiosidade, a participação em grupos de apoio, a terapia com especialistas e outros, 
constituem-se em fatores favoráveis capazes de auxiliar no processo de enfrentamento da desordem e incertezas. Outro ponto positivo foi a execução de atividades interativas diárias de mães, as quais beneficiam os diferentes atores envolvidos.

Em relação aos aspectos desfavoráveis, os vizinhos parecem não aceitar a reinserção do usuário no convívio comunitário por entenderem que este fere as relações e interações sociais. Assim, a família, especificamente a mãe, busca incansavelmente alternativas para ajudar o filho que vive em função da droga. As estratégias apontadas por elas são as mais diversas, vão desde a violência física até a busca pela espiritualidade, como nos depoimentos abaixo:

Uma vez, eu prendi ele no meu quarto [...]. Deixei-o chaveado. Só soltei ele quando cheguei. Mas, deixei comida, deixei tudo pra ele, e preguei a janela. (F1)

Eu acho, assim: que uma conversa, uma palavra de conscientização, uma palavrinha que vai melhorar [...]. Eu digo: "Deus é que sabe". Eu acredito muito na palavra de Deus. (F6)

Sinto assim, que pelos grupos que eu frequento ou frequentei, que a maioria das mães abandona os filhos, elas largam totalmente seus filhos e ainda muitas te orientam a deixá-los na rua, passando fome. (F9)

Nas falas das mães fica evidente que a sobrevivência do filho perpassa pelas mais diferentes estratégias de enfrentamento. Elas recorreram à variadas condutas, como a reclusão domiciliar do viciado em sua própria residência, a agressão física, com o intuito de intimidálo a permanecer em casa, a super-proteção e até mesmo a negação da realidade existencial.

\section{Deparando-se com as consequências}

Na busca pela sobrevivência, marcada pelas incertezas, a família sofre várias consequências, as quais refletem diretamente no ambiente familiar como um todo. Dessa forma, os membros vivenciam constante sofrimento e momentos de desespero que desorganizam a sua vida, tanto familiar quanto social, bem como acarretam consequências físicas, psicológicas, emocionais, financeiras, entre outras. A seguir alguns depoimentos que retratam esta realidade:

Eu sempre gostei de ler e sempre tive muitos livros lendo ao mesmo tempo. Só que, ultimamente, eu não entendo mais o que eu leio, sabe? Eu estou sem entendimento. Ojornal, às vezes, eu leio duas ou três vezes, e não entendo. (F4)

Depois que ele começou a usar drogas, toda a familia adoeceu junto. Eu até estou tomando remédio para depressão e, ainda bem, que estou melhorando prá poder cuidar dele. (F2)

Chegou num determinado domingo que eu decidi ir até a garganta do diabo, deixar o carro estacionado e me atirar, se eu ia morrer, não sei [...]. Comecei a ouvir uma voz dizendo não, então me surgiu um pensamento, sem eu querer, que Deus estava falando comigo. (F13)

Percebe-se que os familiares, na luta pela sobrevivência de um de seus membros, passam por diversas provações. A desestruturação familiar mostrou-se presente em todos os relatos. A preocupação constante, acompanhada pelo desgaste físico e mental, contribuiu para reduzir do seu desempenho intelectual. Já, outras mães passaram por momentos de depressão e confusão mental, e seus anseios suicidas.

\section{DISCUSSÃO}

O crack, em seu contexto global, atinge as mais variadas classes sociais. De modo geral, os participantes do estudo evidenciam um contexto de incertezas, insegurança e questionamentos, para os quais não encontram respostas. A consequência de como a droga influenciará no futuro dos indivíduos que fazem uso do crack é vista com preocupação e, inclusive, medo e desesperança.

Com relação ao familiar de usuário de crack, são identificados alguns sentimentos que remetem à vontade de ajudar, à tolerância, ao desespero, à raiva, ao medo e à impotência, diante da droga ${ }^{(12-13)}$. Por muitas vezes, os familiares dos sujeitos que estão à mercê do vício acabam por manterem uma postura equivocada com o intuito de proteção, visando à sobrevivência dos indivíduos, tornandose cúmplices na aquisição da substância, para manter, em última análise, a vida como depoimento de familiar (F4).

Entre os fatores preponderantes que influenciam neste processo de dependência da droga, apresentam-se interveniências de ordem positiva e de ordem negativa que, de alguma maneira, contribuem para a sobrevivência e manutenção do vício. A existência de terapias, envolvendo equipes multiprofissionais, que têm como objetivo não somente a recuperação, mas também a inserção social destes sujeitos, tem papel fundamental. 
A droga, por ser considerada um desagregador de famílias, por influenciar diretamente nas relações, tanto internas quanto externas, merece discussões e aprofundamentos em todas as áreas do conhecimento. A imagem construída, muitas vezes de forma negativa, somado ao preconceito, ao medo e à aversão ao usuário de crack toma proporções que figuram a demonização do viciado ${ }^{(13-14)}$.

Entre os vários aspectos apresentados pelos familiares acerca do fenômeno crack e diante das condições de incertezas, as estratégias de sobrevivência da própria família, perpassam as mais variadas ações. $\mathrm{Na}$ busca de alternativas para que a convivência com esta situação seja possível, a religiosidade aparece como um fator importante e animador. A religião exerce um papel fundamental no processo de prevenção e no tratamento de drogas, contemplando, tanto os usuários quanto os familiares que vivenciaram momentos traumáticos, desde o início da dependência da droga até a reinserção social ${ }^{(15-16)}$.

Pesquisas revelam que a prática religiosa constituise em uma poderosa fonte de conforto, esperança e significado, especialmente, no enfrentamento de doenças crônicas, tanto físicas quanto mentais. Cerca de 500 estudos, realizados no ano 2000, que examinaram os efeitos e relações das práticas religiosas no cotidiano da saúde, revelam que existe uma associação positiva, com melhora no estado mental e no bem-estar em geral, bem como resultados mais rápidos que as terapias seculares, em pacientes religiosos ${ }^{(15)}$. As práticas religiosas, em outras palavras, ajudam os pacientes a lidar melhor com as doenças e, dessa forma, ajudam a prevenir comportamentos autodestrutivos, como o abuso de substâncias químicas, entre outras.

Outro fator apontado pelos familiares refere-se à violência que surge como busca desesperada pela conscientização, como uma medida punitiva pelo uso do psicotrópico. A agressão física é vista como uma medida de alerta, que é realizada no intuito de evitar a aproximação com a droga, julgando entre o certo e errado o uso da droga. Não havendo a possibilidade de diálogo e esta sendo uma tentativa sem sucesso, a resposta, por meio da violência, proporciona uma impotência familiar diante contexto ${ }^{(13)}$.

O uso de psicotrópicos é um aspecto relevante, pois, de maneira direta ou indireta, acaba por afetar todos os integrantes deste meio ${ }^{(17)}$. A desestruturação da família surge como uma das principais consequências do uso do crack, visto que afeta profundamente as relações, a convivência e a interdependência entre seus componentes.

Observa-se maior conscientização por parte do poder público no desenvolvimento de medidas que visam o combate ao uso do crack e a minimização das consequências refletidas no convívio familiar. Conforme iniciativa do governo federal há uma mobilização para implementação de centros regionais de referência em crack e outras drogas com apoio de universidades ${ }^{(18)}$. Com isso, é evidenciado um maior comprometimento por parte do Estado diante do problema, no sentido de conter a expansão do uso dessa droga e a contribuição com as condições de incertezas vivenciadas pelos familiares.

Necessita-se, no entanto, maior efetividade nas políticas direcionadas para a reinserção social e ocupacional dos usuários e familiares, visto que o combate ao crack somente será possível diante de estratégias sistêmicas, que envolvam as múltiplas relações e interações sociais. São necessárias intervenções imediatas de desintoxicação ao usuário, garantia de apoio aos demais membros da família e, por fim, um acompanhamento domiciliar, de acordo com a realidade vivenciada por cada família.

\section{CONSIDERAÇÕES FINAIS}

As repercussões do fenômeno crack no cotidiano de familiares estão basicamente associadas à sobrevivência em condições de incerteza. A insegurança permanece uma constante, posto que os familiares não estão preparados para lidar com tamanha desordem e/ ou desorganização e/ou reorganização familiar provocadas pelas condições de incerteza.

Os resultados da pesquisa evidenciaram que as repercussões de familiares de usuários de crack estão relacionadas a sinais e sintomas aparentes e inaparentes. Ao mesmo tempo em que sentem dúvidas, incertezas, medos ou temores de toda ordem, os familiares também sentem vergonha, sensação de culpa e impotência, diante do inesperado, e para o qual não foram preparados e não encontram respostas.

O estudo evidencia que é preciso, além de uma atitude responsável e comprometida com os familiares de usuários de crack, desenvolver uma atitude de intervenção proativa, comprometida com o ser humano integral. É preciso repensar o ser e o agir dos profissionais da saúde, reconhecendo as incertezas, desordens e contradições, não como um fim em si mesmo, mas como indutoras de novos referenciais, mais abertos e flexíveis para com as questões sociais emergentes.

O estudo alerta, em suma, para a necessidade de ampliar os conhecimentos acerca das questões que envolvem o crack. Alerta, para uma nova atitude 
profissional para com a família dos usuários que, não raramente, passam a ser a principal vítima do processo. Os pesquisadores e profissionais em geral precisam unir forças e empenharem-se na busca de estratégias integradas e comprometidas com o ser humano como um todo, isto é, como um ser singular e multidimensional.

\section{REFERÊNCIAS}

1. Focchi GRA, Scivoletto S. Drogas desenhadas: novas drogas de abuso? J. Bras. Psiquiatr. 2000;49(10/12):383-6.

2. Scivoletto S, Boarati MA, Turkiewicz G. Emergências psiquiátricas na infância e adolescência. Rev. Bras. Psiquiatr. 2010;32(2):112-20.

3. Ministério da Saúde (BR). Coordenação Nacional de Saúde Mental, Álcool e outras Drogas. O crack: como lidar com este grave problema. 2010. [acesso em 12 dez 2010]. Disponível: http://portal.saude.gov.br/portal/ saude/visualizar_texto.cfm?idtxt $=33717 \&$ janela1

4. Ministério da Saúde (BR). Ministério da Saúde irá dobrar leitos de internação para usuários de crack e outras drogas. Brasília. 2010. [acesso em 24 fev 2011]. Disponível: http://portal.saude.gov.br/portal/aplicacoes/ noticias/default.cfm?pg=dspDetalheNoticia\&id area $=124 \& C O \_$NOTICIA $=11327$.

5. Suárez RE, Galera SAF. Discurso de los padres sobre el uso de drogas lícitas e ilícitas percibido por estudiantes universitários. Rev. Latino-Am. Enfermagem. 2004; 12(especial):406-11.

6. Funchal E, Lenardt MH, Labronici LM, Polak YSN. Rituais vivenciados pelo corpo fumante. Cogitare enferm. 2005;10(1):53-9.

7. Bernardy CCF, Oliveira MLF. O papel das relações familiares na iniciação ao uso de drogas de abuso por jovens institucionalizados. Rev Esc Enferm USP. 2010;44(1):11-7.

8. Strauss AL, Corbin J. Basics of qualitative research: Grounded Theory procedures and techniques. Newbury Park: Sage Publications; 1990.

9. Charmaz K. Constructing Grounded Theory: a practical guide through qualitative analysis. Rohnert Park: Sage Publications; 2006.

10. Corbin J, Hildenbrand B. Qualitative forschung. In: Allhoff R, Schaeffer D. Handbuch pflegewissenschaft. München: Juventa; 2003. p.159-84.
11. Ministério da Saúde (BR). Conselho Nacional de Saúde. Diretrizes e normas regulamentadoras de pesquisa envolvendo seres humanos. Resolução n. 196, de 10 de outubro de 1996. Brasília; 1996.

12. Arendt H. A condição humana. $10^{\mathrm{a}}$ ed. Rio de Janeiro: Forense Universitária; 2009.

13. Nonticuri AR. As vivências de adolescentes e jovens com o crack e suas relações com as políticas sociais protetoras neste contexto. [dissertação]. Pelotas (RS): Universidade Católica de Pelotas; 2010.

14. Beck AJ. Dependência do crack: repercussões para o usuário e sua família. [trabalho de conclusão de curso]. Porto Alegre (RS): Universidade Federal do Rio Grande do Sul; 2010.

15. Koenig HG. Religion, spirituality, and medicine: research findings and implications for clinical practice. SMJ. 2003;97(12):1194-200.

16. Sanchez ZVDM, Nappo SA. A religiosidade, a espiritualidade e o consumo de drogas. Rev. psiquiatr. clín. 2007;34(1):73-81.

17. Aratangy LR. Doces venenos: conversas e desconversas sobre drogas. 15 ed. São Paulo: Olho d'água; 2008.

18. O PAC do crack. Diário de Santa Maria [Internet] Santa Maria (RS); 2011 [acesso em 25 abr 2011]. Disponível: http://www.clicrbs.com.br/dsm/rs/ impressa/4,41,3213854,16537

Cogitare Enferm. 2012 Abr/Jun; 17(2):248-54 